\title{
The international classification for functioning, disability and health
}

\author{
A challenge and a need for rheumatology
}

Annelies Boonen • Johannes J. Rasker • Gerold Stucki

Received: 12 April 2007 / Accepted: 12 April 2007 / Published online: 9 June 2007

(C) Clinical Rheumatology 2007

Health information is the glue that holds a health system together. In most countries stronger, more integrated information systems are required [1].

The rheumatologic community is in a leading position for the development of International Classification of Functioning, Disability and Health (ICF) Core Sets and the research into the validity and application of the ICF. We can be proud of this achievement, but not all of us are aware of this new development. What is the ICF?

Rheumatologic conditions have major impact on patients. Apart from symptoms such as pain, stiffness, and fatigue, patients are limited in activities and restricted in participation in society [2]. When unable to continue paid work, for example, there are important consequences for the patients,

\footnotetext{
A. Boonen $(\bowtie)$

Department of Internal Medicine,

Division of Rheumatology and Caphri Research Institute, University Hospital Maastricht,

P.O.Box 5800, 6202 AZ Maastricht, The Netherlands

e-mail: aboo@sint.azm.nl

J. J. Rasker

Faculty of Behavioural Sciences, Department of Psychology and Communication of Health and Risk, University Twente,

Enschede, The Netherlands

G. Stucki

Department of Physical Medicine and Rehabilitation, Ludwig-Maximilian University,

Munich, Germany

G. Stucki

ICF Research Branch, WHO FIC Collaborating Center (DIMDI), IHRS, Ludwig-Maximilian University,

Munich, Germany
}

their families, but also for society. A major goal of the management of rheumatic diseases is to maintain or restore functioning. This contributes to the well-being of the patients, their families, and other caregivers. It is clear that maintaining function requires more than control of disease activity. By using the ICF, which was developed by the World Health Organization (WHO), we can obtain information on all three areas that are important for global functioning: body functions and structures, activities (actions by an individual), and participation (involvement in life situations) [3].

The ICF is one of the three reference classification systems that were proposed and developed by the WHO and belong to the Family of International Classifications. The main aim of the classification systems is to improve integration of health information. The International Classification of Diagnosis (ICD) is well known and widely applied [4]. The ICF was developed from the older International Classification of Impairments, Disabilities, and Handicaps (ICIDH) and accepted in 2001 [3]. It is increasingly recognized as an important classification in clinical medicine, outcome research, and healthcare organization. The International Classification of Health Interventions (ICHI) is proposed as the newest member of the family, and its development has just started [1].

The WHO aims to implement effectively the ICF worldwide and formulated strategic directions in which the three following are the most relevant: (1) The ICF has to become the framework to classify function, (2) easy-to-use ICF linked instruments should be developed to assess functional outcome as well as effectiveness of interventions, and (3) the level and quality of implementation of the ICF should be improved to increase quality and comparability 
of health and disability statistics for national and international purposes [1].

In this review, the ICF framework and classification are explained from the broader perspective of the history of outcome assessment. Healthcare areas in which the ICF can be useful will be addressed. Finally, the strengths of the ICF will be challenged by the research agenda.

\section{The ICF as the universal framework for functioning: a historical view}

For centuries, diagnostic and outcome assessments in medicine were limited to the assessment of the direct physiological consequence of the disease. Research concentrated on methods to evaluate the biological disease process such as body temperature or blood pressure, identification of microbial pathogens, or detection of laboratory abnormalities reflecting organ dysfunction. The need to measure and quantify the effect of (ill) health on human well-being and functioning is a recent phenomenon in the long history of medicine. This was inspired by the need to be able to measure the function of a patient as well as the effects of treatments. In rheumatoid arthritis (RA), the first classification of function was introduced in 1949 by Steinbrocker [5], and the first instrument to measure functioning, the Health Assessment Questionnaire (HAQ), was proposed by Fries in 1980 [6]. Since then, many other instruments emerged to measure functioning either disease specific [7-10], generic [11, 12], or for specific aspects of functioning such as hand function in RA [13-15]. However, these classifications and instruments are based on older models of functioning, mainly known as the impairmentdisability-handicap concept (Fig. 1) and have several drawbacks $[16,17]$. They apply a negative terminology, are unidirectional, and reflect the narrow biomedical view on function by ignoring the importance of environmental (social) and personal factors for functioning. These shortcomings are addressed by the ICF framework.

Functioning is now understood as the human experience in relation to body functions and structures, activities and participation in the interaction with health conditions, personal and environmental factors (Fig. 2). By using the

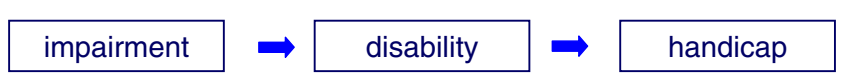

Negative terminology Unidirectional

Lack of environmental (social) and personal factors

No detailed classification

Fig. 1 Representation of the historical view on functioning that represents the typical biomedical model of disease

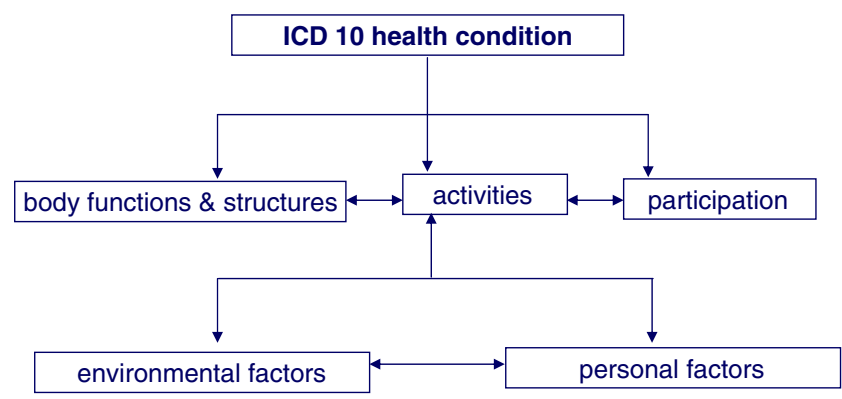

Fig. 2 The current framework of disability - the WHO ICF

term participation instead of handicap, a positive terminology is proposed. By including the environmental and personal factors, the bio-psychosocial model is accepted [2]. Finally, the different components of the framework recognize human functioning as a complex interaction of the different areas. It is clear that the ICF framework is in line with the WHO's definition of health that includes "physical, mental and social wellbeing" [18]. Although developed to describe functioning of people with a (ill) health condition, it may indeed also be applied for healthy subjects because functioning is a universal experience.

\section{Why is the ICF called "the universal" classification for functioning?}

\section{The ICF Core Sets}

The ICF offers a framework that conceptualizes functioning but is also a classification comprising 1,454 descriptions that cover all aspects of functioning and are called ICF categories. These categories are structured hierarchically into different chapters that, on their turn, belong to the ICF components: body functions and structures (categories designed a number preceded by "b" or "s" respectively), activities and participation (categories designed as a number preceded by " $d$ "), environmental factors (categories designed as a number preceded by "e"), and personal factors (categories not yet defined; Fig. 3).

To apply the ICF in practice, either in patients with a specific condition (like RA) or in specific healthcare situations (like acute or post-acute care), ICF Core Sets are being developed. These comprise specific categories relevant for a particular condition or a specific situation [19].

At present, first versions of ICF Core Sets have been published for 12 chronic health conditions among which 5 are for musculoskeletal diseases: RA, osteoporosis, osteoarthritis, low back pain, and chronic widespread pain [20-24]. The first versions of these ICF Core Sets are currently undergoing a worldwide testing and validation, including a cooperation 
Fig. 3 Structure of the ICF classification

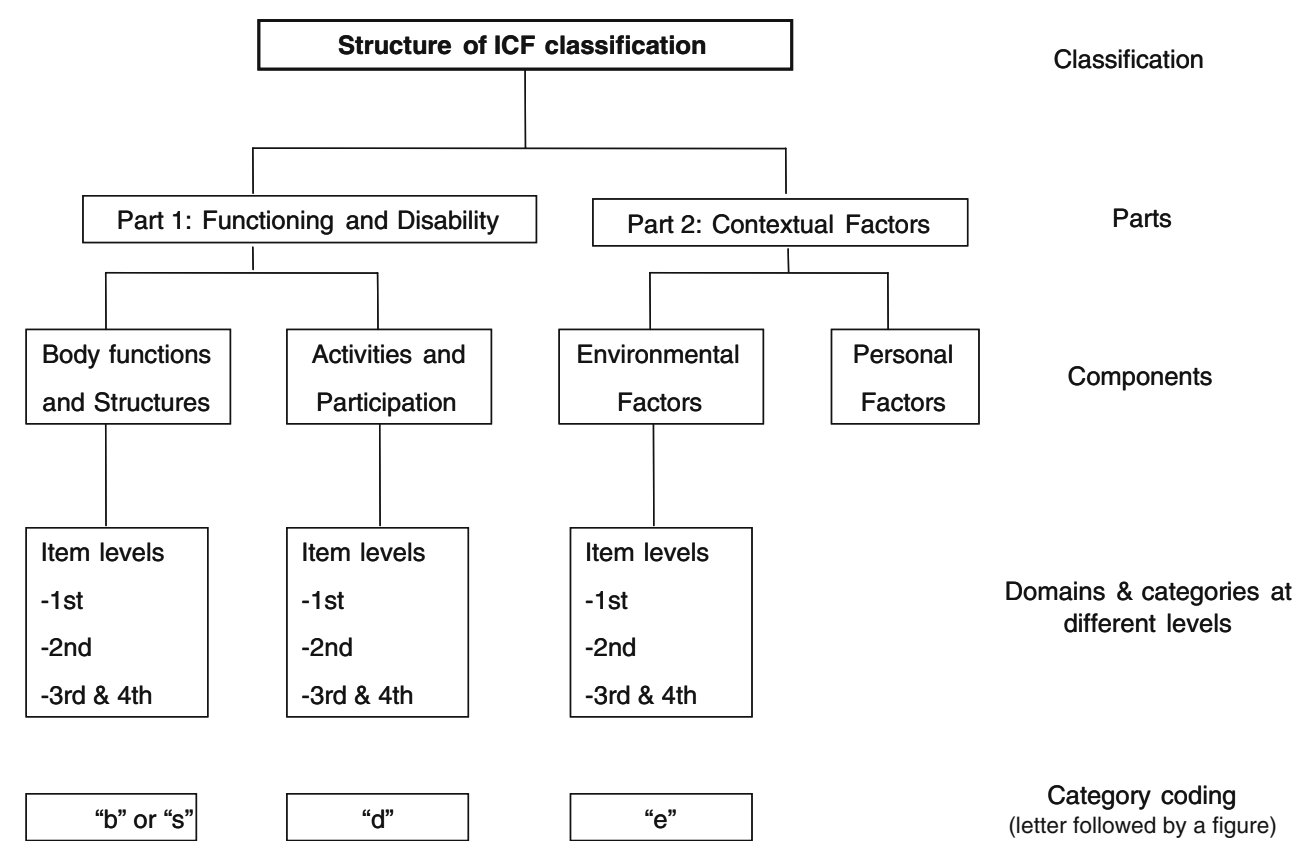

project with EULAR for the five musculoskeletal ICF Core Sets. Additional ICF Core Sets for musculoskeletal disease are currently also being developed for psoriatic arthritis, ankylosing spondylitis, scleroderma, lupus, and gout $[25,26]$. For the acute hospital and early post-acute rehabilitation facilities, ICF Core Sets have been developed for musculoskeletal, cardiovascular, and neurological conditions [27]. Arthritis-specific ICF Core Sets have been developed for the acute and early post-acute situation [28, 29].

Upon completion and experience with the development of these ICF Core Sets, a Generic ICF Core Set is being developed that aims to include categories necessary to represent the experience of human functioning irrespective of the underlying health condition.

When developing the ICF Core Sets, a standardized approach is applied in which the perspective of patients, different types of health care providers, and outcome researchers are taken into account [30]. As the categories of the specific ICF Core Sets originate from the universal ICF, the classifications can be easily understood across professionals and across conditions. The common definition of the categories and the standardized development of the Core Sets explains why the ICF is called a universal classification.

\section{How to measure the ICF categories}

It should be emphasized that Core Sets aim at first to define "what" should be assessed when classifying function. "How" these categories should be assessed is a different issue.
It is specifically mentioned in the WHO business report that it is by no means the aim of the ICF to replace validated existing instruments. In contrast, it is likely that they will have an essential role to measure particular parts of the ICF.

The ICF classification provides for each category an optional scoring, the so-called ICF qualifiers. Qualifiers are numeric codes that specify the extent or the magnitude of the functioning or disability in that category or the extent to which an environmental factor is a facilitator or barrier. Such a qualifier may be directly be applied or can serve as reference scale if specific measures are being used. According to the ICF qualifier, the level of impairments in body functions and body structures or limitations or restrictions in activities and participation can be indicated on a 0 (no) to 4 (complete) scale. A "c" indicates the category is impaired or limited as a consequence of comorbidity, " 8 " that the level of impairment cannot be specified, and "9" that the category is not applicable. For the environmental factors, patients can specify the category is a barrier $(-)$ or a facilitator $(+)$ [31]. The qualifiers can be directly applied to the categories or can serve as reference scale if specific measures are being used to qualify the categories.

The direct application of the ICF qualifier is challenging. First, the language of the ICF is sometimes difficult to understand. Secondly, the number of response categories may exceed the number relevant for patients and health professionals in clinical practice. Therefore, it is often preferable to use reliable and validated instruments for the measurement of specific ICF categories. While such instru- 
Fig. 4 The ICF as interface functioning and existing instruments measuring function between concepts relevant for

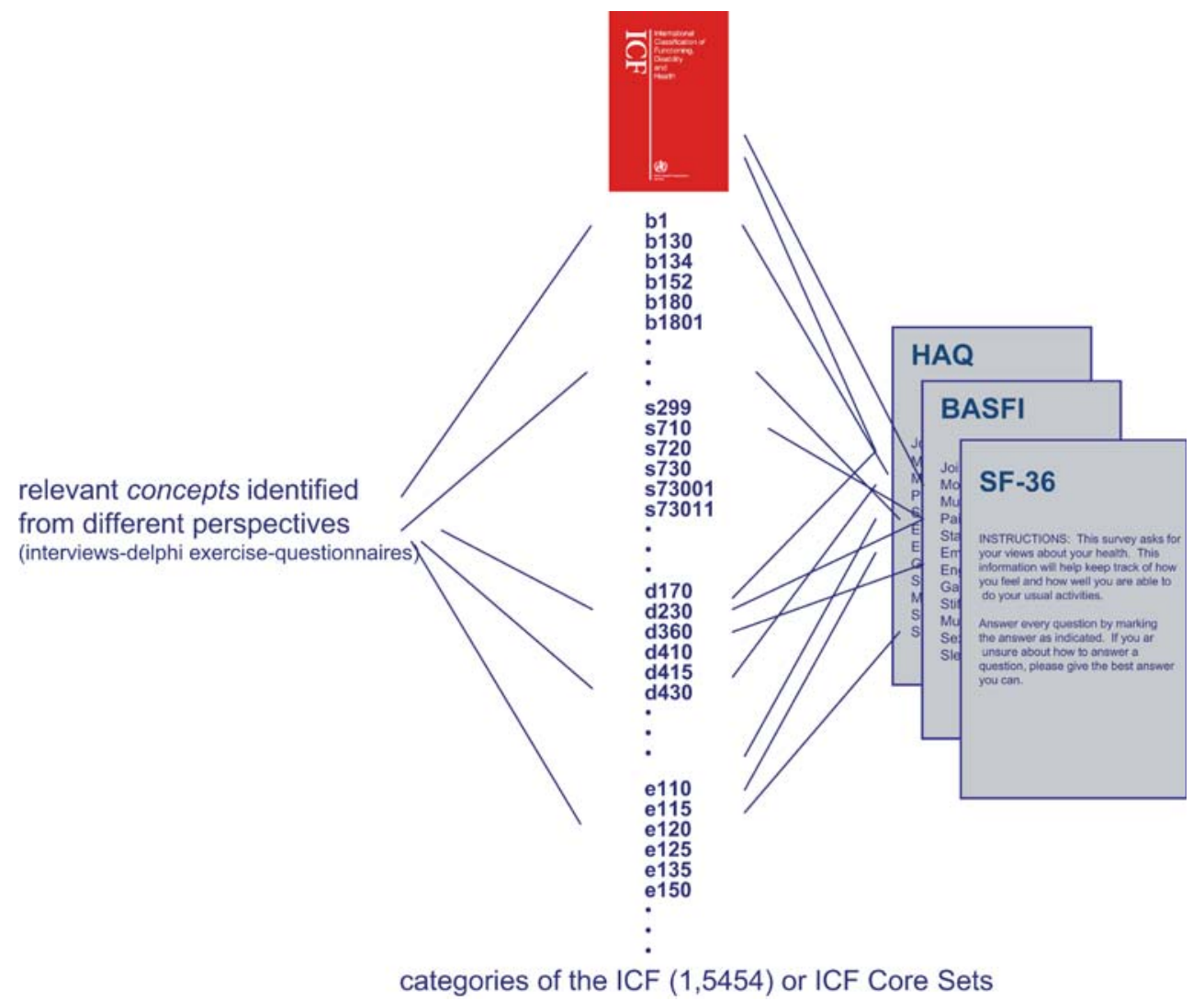

ments often differ on important aspects from the ICF classification, they can be very useful to operationalize the ICF in specific situations and for specific categories. Figure 4 represents how the ICF is the "universal" interface between agreed upon categories and existing measures.

\section{Applications of the ICF Core Sets}

The main stakeholders of the ICF are clinicians, researchers, and decision makers on the governmental level and, last but not least, governments. Most certainly, also patient organizations, healthcare organizations (health insurance companies, home care organizations, social security services), and media systems can benefit from the ICF [2].

As the ICF can classify functioning at the group but also at the individual level, it can be used in clinical practice. Especially in rehabilitation medicine, the comprehensive approach contributes to the planning of tailor made care for patients within the framework of the bio-psychosocial model. The assessment for vocational rehabilitation of a patient with RA, for example, requires careful evaluation of impairments in body functions (such as pain, energy level, sleep) and body structures (such as damage to the hand joints), limitations in activities (fine hand use, walking) and participation (using transportation services, self-care), but also identification of relevant environmental factors (medication, adaptations, attitudes of colleagues, attitudes of family members) and personal factors (age, marital state, educational level, coping strategies, illness perceptions) [32]. Identification of the individualized relevant categories will make it possible to set priorities for treatment and to identify the health professionals responsible to execute each of the identified priorities [33]. While the contribution of allied health professionals is recognized, the ICF will help defining the specific role and responsibilities of each professional for the different categories [34]. The common ICF framework and language will improve not only communication among the different healthcare providers but also communication with the patients and nonmedical environment such as family and employers.

For researchers with an interest in outcome assessment, the ICF offers challenging opportunities. ICF Core Sets are useful for the design, the evaluation, and the reporting of studies examining the longitudinal course of disease or the efficacy and effectiveness of interventions. In the study design, ICF-based comparisons of candidate measures will help to select aspects of functioning, which most appropriately cover the patients' problems that should be improved. Researchers have to pinpoint the targets and explanatory 
variables. Currently, we often lack an understanding of the mechanism that leads to progression of disease or improvement based on an intervention. The ICF offers an opportunity that not only enables to report about statistical and clinically relevant differences but also to demonstrate the mechanism of changes (over time or during interventions) on the level of functioning. Such analyses are only possible if at least a minimum set of variables covering all aspects relevant to people with the condition are covered. In addition, the ICF-based approach to follow cohorts or intervention studies will enable comparison of studies not only in people with the same condition but also across diseases when considering the Generic ICF Core Set in the study design.

From the perspective of the governments and healthcare organizations, there is a great interest in the ICF. For the WHO, it has a priority to demonstrate the utility and feasibility of using ICF in areas of strategic importance such as health and disability reporting, outcome measurement for clinical and epidemiological use, and disability assessment and certification by 2008. ICF-based data sets including ICF population norms and disability prevalence rates should be available by 2010 . Healthcare organizations explore the application of the ICF for disability assessments, eligibility of technical aids and home care, and organization of social services. Such data will contribute to insight in planning of social security systems and home care, eligibility assessment for disability pensions, and technical aids.

\section{Future challenges}

While it is obvious that the ICF has made tremendous steps forward since its conception, it is clear at the same time that there is still a challenging way to go.

The first priority is to develop a classification for personal factors and the development of the Generic Core Set. As for any instrument, the classification has to prove it can pass the validity filter, especially with regard to discrimination and feasibility. From limited research, it is suggested that the reliability can be improved, probably because the ICF language is difficult to understand and because the qualifiers show differential functioning [35]. This is especially true for many categories referring to participation and for most environmental factors that were relevant in all Core Sets and for which no other but ICFbased classifications exist. While there are many studies that address work participation, few validated instruments exist to assess absenteeism [36-39]. Even fewer instruments are developed to assess participation in nonworkrelated social activities, except some items of generic instruments such as short-form (SF) 36 [12] and of the Arthritis Impact Measurement Scales-2 (AIMS2) [40].

To improve feasibility, expanding the efforts to increase understanding and application of the ICF among a wider audience are still necessary. On this line, the exact approach on how existing measures can be integrated into the ICF classification needs further clarification and consensus. This will include the exploration of statistical methods to handle hierarchical data and complex relationship between the categories belonging to the components.

\section{Conclusion}

The adoption of the ICF in 2001 as a framework and classification was the recognition of the importance of the bio-psychosocial perspective to account for the human experience of functioning. Being a universal language, the ICF will improve our insight into the complexity of human functioning, help tailor-made care for the individual patient, and improve design and reporting of observational and interventional studies. The rheumatologic community has to be merited to be in a leading position for the development of Core Sets and the research into validity and application of the ICF. This illustrates again how, for the rheumatologist, the patient needs to be the starting as well as endpoint of his devotion.

\section{References}

1. WHO (2005) WHO business plan for classifications. Building blocks of health information, report no.: V 1.0. World Health Organization, Geneva

2. Cornelissen PG, Rasker JJ, Valkenburg HA (1988) The arthritis sufferer and the community: a comparison of arthritis sufferers in rural and urban areas. Ann Rheum Dis 47:150-156

3. WHO (2001) The International Classification of Functioning, Disability and Health. World Health Organization, Geneva

4. WHO (1992) International statistical classification of diseases and related health problems. World Health Association, Geneva

5. Steinbrocker O (1969) Prognosis for employability in the major arthritides rheumatoid arthritis, osteoarthritis and gout. Pa Med $72: 82-85$

6. Fries JF, Spitz P, Kraines RG, Holman HR (1980) Measurement of patient outcome in arthritis. Arthritis Rheum 23:137-145

7. Bellamy N, Buchanan WW, Goldsmith CH, Campbell J, Stitt LW (1988) Validation study of WOMAC: a health status instrument for measuring clinically important patient relevant outcomes to antirheumatic drug therapy in patients with osteoarthritis of the hip or knee. J Rheumatol 15:1833-1840

8. Calin A, Nakache JP, Gueguen A, Zeidler H, Mielants H, Dougados M (1999) Defining disease activity in ankylosing spondylitis: is a combination of variables (Bath Ankylosing Spondylitis Disease Activity Index) an appropriate instrument? Rheumatology 38:878-882

9. Burckhardt CS, Clark SR, Bennett RM (1991) The fibromyalgia impact questionnaire: development and validation. J Rheumatol 18:728-733

10. Lequesne M (1991) Indices of severity and disease activity for osteoarthritis. Semin Arthritis Rheum 20(6 Suppl 2):48-54 
11. Hunt SM, McKenna SP, McEwen J, Williams J, Papp E (1981) The Nottingham Health Profile: subjective health status and medical consultations. Soc Sci Med 15(3 Pt 1):221-229

12. Ware JE Jr, Sherbourne CD (1992) The MOS 36-item short-form health survey (SF-36). I. Conceptual framework and item selection. Med Care 30:473-483

13. Backman C, Mackie H, Harris J (1991) Arthritis hand function test: development of a standardised assessment tool. Occup Ther J Res 11:246-256

14. Dellhag B, Bjelle A (1995) A grip ability test for use in rheumatology practice. J Rheumatol 22:1559-1565

15. Duruoz MT, Poiraudeau S, Fermanian J, Menkes CJ, Amor B, Dougados M, Revel M (1996) Development and validation of a rheumatoid hand functional disability scale that assesses functional handicap. J Rheumatol 23:1167-1172

16. Nagi S (1991) Disability concepts revisited: implications for prevention. In: Pope A, Tarlov V (eds) Disability in America: towards a national agenda for prevention. National Academy Press, Washington, DC

17. WHO (1980) International Classification of Impairments, Disabilities and Handicaps: a manual for classification relating to the consequence of disease. Geneva

18. WHO (1947) Constitution of the World Health Organization. World Health Organization, Geneva

19. Stucki G, Cieza A, Ewert T, Kostanjsek N, Chatterji S, Ustun TB (2002) Application of the International Classification of Functioning, Disability and Health (ICF) in clinical practice. Disabil Rehabil 24:281-282

20. Cieza A, Schwarzkopf S, Sigl T, Stucki G, Melvin J, Stoll T, Woolf A, Kostanjsek N, Walsh N (2004) ICF Core Sets for osteoporosis. J Rehabil Med 44 Suppl:81-86

21. Cieza A, Stucki G, Weigl M, Disler P, Jackel W, van der Linden S, Kostanjsek N, de Bie R (2004) ICF Core Sets for low back pain. J Rehabil Med 44 Suppl:69-74

22. Cieza A, Stucki G, Weigl M, Kullmann L, Stoll T, Kamen L, Kostanjsek N, Walsh N (2004) ICF Core Sets for chronic widespread pain. J Rehabil Med 44 Suppl:63-68

23. Dreinhofer K, Stucki G, Ewert T, Huber E, Ebenbichler G, Gutenbrunner C, Kostanjsek N, Cieza A (2004) ICF Core Sets for osteoarthritis. J Rehabil Med 44 Suppl:75-80

24. Stucki G, Cieza A, Geyh S, Battistella L, Lloyd J, Symmons D, Kostanjsek N, Schouten J (2004) ICF Core Sets for rheumatoid arthritis. J Rehabil Med 44 Suppl:87-93

25. Sigl T, Cieza A, van der Heijde D, Stucki G (2005) ICF based comparison of disease specific instruments measuring physical functional ability in ankylosing spondylitis. Ann Rheum Dis 64:1576-1581

26. van Echteld I, Cieza A, Boonen A, Stucki G, Zochling J, Braun J, van der Heijde D (2006) Identification of the most common problems by patients with ankylosing spondylitis using the
International Classification of Functioning, Disability and Health. J Rheumatol 33:2475-2483

27. Stucki G, Ustun TB, Melvin J (2005) Applying the ICF for the acute hospital and early post-acute rehabilitation facilities. Disabil Rehabil 27:349-352

28. Zochling J, Grill E, Scheuringer M, Liman W, Stucki G, Braun J (2006) Identification of health problems in patients with acute inflammatory arthritis, using the International Classification of Functioning, Disability and Health (ICF). Clin Exp Rheumatol 24:239-246

29. Stoll T, Brach M, Huber EO, Scheuringer M, Schwarzkopf SR, Konstanjsek N, Stucki G (2005) ICF Core Set for patients with musculoskeletal conditions in the acute hospital. Disabil Rehabil 27:381-387

30. Cieza A, Ewert T, Ustun TB, Chatterji S, Kostanjsek N, Stucki G (2004) Development of ICF Core Sets for patients with chronic conditions. J Rehabil Med 44 Suppl:9-11

31. International Classification of Functioning, Disability and Health (2001) World Health Organization, Geneva

32. Heerkens Y, Engels J, Kuiper C, Van der Gulden J, Oostendorp R (2004) The use of the ICF to describe work related factors influencing the health of employees. Disabil Rehabil 26: 1060-1066

33. Heerkens Y, van der Brug Y, Napel HT, van Ravensberg D (2003) Past and future use of the ICF (former ICIDH) by nursing and allied health professionals. Disabil Rehabil 25:620-627

34. Taal E, Bobietinska E, Lloyd J, Veehof M, Rasker WJ, Oosterveld FG, Rasker JJ (2006) Successfully living with chronic arthritis. The role of the allied health professionals. Clin Rheumatol 25:189-197

35. Uhlig T, Lillemo S, Moe RH, Stamm T, Cieza A, Boonen A, Mowinckel P, Kvien TK, Stucki GD (2007) Reliability of the ICF core set for rheumatoid arthritis. Ann Rheum Dis

36. Verstappen SM, Bijlsma JW, Verkleij H, Buskens E, Blaauw AA, ter Borg EJ, Jacobs JW (2004) Overview of work disability in rheumatoid arthritis patients as observed in cross-sectional and longitudinal surveys. Arthritis Rheum 51:488-497

37. Boonen A, de Vet H, van der Heijde D, van der Linden S (2001) Work status and its determinants among patients with ankylosing spondylitis. A systematic literature review. J Rheumatol 28: 1056-1062

38. Boonen A (2005) Everyone has the right to work. J Rheumatol 32 (4):571-574

39. Escorpizo R, Bombardier C, Boonen A, Hazes JM, Lacaille D, Strand CV, Beaton DE (2007). Worker productivity outcome measures in arthritis. J Rheumatol 34:1372-1380

40. Meenan RF, Mason JH, Anderson JJ, Guccione AA, Kazis LE (1992) AIMS2. The content and properties of a revised and expanded Arthritis Impact Measurement Scales Health Status Questionnaire. Arthritis Rheum 35:1-10 